\title{
REVISITING THE YORUBA ETHNOGENESIS: A RELIGIO- CULTURAL HERMENEUTICS OF ANCIENT EGYPTIAN TEXTS
}

\author{
Emmanuel Folorunso Taiwo* \\ \& \\ Aghedo Paul Daniel* \\ http://dx.doi.org/10.4314/og.v11i 1.9
}

\begin{abstract}
The ethnogenesis of the Yoruba has been a subject of various historical critical arguments in recent scholarship. Local historians and their foreign counterpart have explored different scholarly models to ascertain the origin of the Yoruba race. A sizeable number of these accounts usually explore the historical evidence from ancient Egypt. Although, such historical traditions differ from one school of thought to another, some modern historians of Yoruba descent insist that the Yoruba originated from Egypt. In recent times this development has generated debates; though, some schools of thought have argued that there are indices of religio-cultural affinity between the Yoruba and the ancient Egyptians, yet others maintain that the presence of white skinned Egyptians and the Arabs, do not seem to confirm that the Yoruba originated from Egypt. This paper seeks to explore the possibilities of an Egypto-Yoruba ethnogenesis by examining the religio-cultural elements in ancient Egyptian texts.
\end{abstract}

\section{Keywords: Ancient Egyptians, Yoruba, Ethnogenesis, religio- cultural, Ma'at}

\section{Introduction}

There are two sources of the Yoruba ethnogenesis, which this study intends to explore; the first being the "Ifa corpus", the Yoruba generally believe that this mystical phenomenon has records of the mysteries about the existence of the Yoruba people. Thus, it is Ifa, which can duly explain the origin of the Yoruba. Within the norm of this concept, the Yoruba believes that Olodumare; the supreme God created the universe and the gods. 
Olodumare and the gods created humans; Orishanla, the arch-god played a prominent role. Thus, Ile Ife the traditional home of the Yoruba is believed to be the cradle of all civilizations. Therefore, all human histories began in Ife. The first royal father Oduduwa descended from heaven through a magic chain in IleIfe. ${ }^{1}$ However, most religio-cultural accounts of the Yoruba ethnogenesis often lack elements of modern historical methodology, which quests for historical truth, the accurate dating, verifiable sources, structures, external evidences among others, thus, the information garnered from the Ifa oracle can best be described as myths, such historical trends are not tenable today ${ }^{2}$.

Secondly, historical traditions differ from one school of thought to another, but the common trend that has now become an area of interest for modern historians is the claim that the Yoruba migrated from Egypt. In recent times this development has generated debates; although, some schools of thought argued that there are indexes of religio-cultural relativity between the Yoruba and the ancient Egyptians. Nonetheless, there is an important argument that the present phase of Egypt dominated by the white skinned Egyptians and the Arabs, do not seem to confirm that the Yoruba originated from Egypt.

However, scholars such as Parrinder (1951) and Lucas (1970) have asserted that there is little archaeological evidence that the Egyptians migrated to Yoruba land, adding further that whatever contacts there may have been between the two peoples is traceable to the predynastic and dynastic periods. Hence there is a possibility of influence on the Yoruba. According to $\mathrm{Agai}^{3}$, the religions of Christianity and Islam, colonialism, the ideology that Egypt was the cradle of human civilization, the Yoruba creation myth and many other factors might have influenced the minds of the $20^{\text {th }}$ century writers of West African history to conclude that there was serious contact between them. Besides, this research is carried out with a realization that ancient Egypt was and is still a part of the African continent.

\section{The Similarity in both Religion and Cultures}

The Egyptian and the Yoruba share cultural and religious beliefs; you cannot separate their religious beliefs from their socio-cultural 
existence. Both religions are structured in a way that it dictates the daily routines and even their entire worldview. Both religions are highly philosophical in their facility of norms for social and moral integrity. Agaiet al assert that both the ancient Egyptian and Yoruba cultures; recognize the existence of and supremacy of a supreme being/deity but worshipped local deities and ancestors. The peoples regard their kings as divine authorities, certain animals as sacred, and certain forms of festivals involving dancing and singing were practiced, magic and the use of amulets were important in the daily lives of /and in the afterlife beliefs of both cultures. Body mutilations practiced in Egypt also found its way to the Yoruba, these include circumcision, excision, having and piercing of ears and nose. These Yoruba cultures were also practiced during the predynastic and dynastic periods in ancient Egypt. ${ }^{4}$ In the light of the foregoing; the present study would attempt to explore these religiocultural similarities based on the investigation of ancient Egyptian magical texts, such as Ma'at, among others.

\section{The Egyptian Ma'at}

Ma'at the Goddess of truth, justice and order was important for many reasons in Egyptian society. She plays a key role in most versions of the creation myth and is occasionally called "Mother of the Earth". She was responsible for the balance of the universe and was usually said to be the cause of any fortune (good or otherwise). The concept of Ma'at (order, harmony, balance) was used to explain many important natural occurrences, like the changing of the seasons and the balance between the Nile and the desert.

In Egyptian belief, Ma'at was constantly under threat from the forces of disorder, so all of society was required to maintain it. Again, this has implications for humanity, this meant that all members of society would cooperate and coexist; on the cosmic level it meant that all of the forces of nature - the gods - should continue to function in balance. This latter goal was central to Egyptian religion. The Egyptians sought to maintain Ma'at in the cosmos by sustaining the gods through offerings and by performing rituals, which staved off disorder and perpetuated the cycles of nature ${ }^{5}$. 
The most important part of the Egyptian view of the cosmos was the conception of time, which was greatly concerned with the maintenance of Ma'at. Throughout the linear passage of time, a cyclical pattern recurred, in which Ma'at was renewed by periodic events, which echoed the original creation. Among these events were the annual Nile flood and the succession from one king to another, but the most important was the daily journey of the sun god Ra.

When envisioning the shape of the cosmos, the Egyptians saw the earth as a flat expanse of land, personified by the god Geb, over which the sky goddess known as Nut arched. The two were separated by Shu, the god of air, beneath the earth lay a parallel underworld and under sky, and beyond the skies lay the infinite expanse of $\mathrm{Nu}$, the chaos that had existed before creation. The Egyptians also believed in a place called the Duat, a mysterious region associated with death and rebirth that may have lain in the underworld or in the sky. Each day, Ra traveled over the earth across the underside of the sky, and at night he passed through the Duat to be reborn at dawn.

In Egyptian belief, three types of sentient beings inhabited this cosmos. One was the gods, another was the spirits of deceased humans, who existed in the divine realm and possessed many of the gods' abilities. Living humans were the third category, and the most important among them was the pharaoh, who bridged the human and divine realms.

Egyptian life was based on order and balance in both society and the natural world. Because of this, Ma'at was extremely important and well respected in Egyptian society, and Ma' at was thought to govern nearly every aspect of Egyptian life. Though Ma'at was rarely worshipped in temples, it was important to try and please her on a regular basis. She was the fulcrum on which a spirit was weighed and judged in the afterlife and was therefore constantly present in an Egyptian's everyday life. Much like the Christian "Ten commandment", ancient Egyptians were expected to uphold the "42 Principles of Ma'at" (e.g. do not stea1).

The justice system was there to uphold the values of Ma'at, though she was not directly related to law. People involved in the justice system were called Priests of Ma'at, even the Pharaoh 
Taiwo \& Daniel: Revisiting the Youruba Ethnogenesis...

himself. Ma'at and the Pharaoh were very closely linked. Pharaohs called themselves the Beloved of Ma'at. They had to rule in a way that kept order and harmony. If they didn't, it was believed that chaos would occur. The Egyptians had elaborate beliefs about death and the afterlife; they believed that humans possessed a ka, or lifeforce, which left the body at the point of death. In life, the ka received its sustenance from food and drink, so it was believed that, to endure after death, the ka must continue to receive offerings of food, whose spiritual essence it could still consume. Each person also had a ba, the set of spiritual characteristics unique to each individual. Unlike the ka, the ba remained attached to the body after death. Egyptian funeral rituals were intended to release the ba from the body so that it could move freely, and to rejoin it with the ka so that it could live on as an akh. However, it was also important that the body of the deceased be preserved, as the Egyptians believed that the ba returned to its body each night to receive new life, before emerging in the morning as an $\mathrm{akh}^{6}$.

Originally, however, the Egyptian believed that only the pharaoh had a ba, and only he could become one with the gods; dead commoners passed into a dark, bleak realm that represented the opposite of life. The nobles received tombs and the resources for their upkeep as gifts from the king, and their ability to enter the afterlife was believed to be dependent on these royal favors. In early times the deceased pharaoh was believed to ascend to the sky and dwell among the stars. Over the course of the Old Kingdom (c. 2686-218 1 BC), however, he came to be more closely associated with the daily rebirth of the sun god $\mathrm{Ra}$ and with the underworld ruler Osiris as those deities grew more important.

During the late Old Kingdom and the First Intermediate Period (c. 2181-2055 BC), the Egyptians gradually came to believe that possession of a ba and the possibility of a paradisiacal afterlife extended to everyone. In the fully developed afterlife beliefs of the New Kingdom, the soul had to avoid a variety of supernatural dangers in the Duat, before undergoing a final judgment known as the 'Weighing of the Heart". In this judgment, the gods compared the actions of the deceased while alive (symbolized by the heart) to Ma'at, to determine whether he or she had behaved in accordance 
with Ma'at. If the deceased was judged worthy, his or her ka and ba were united into an akh.

Several beliefs coexisted about the akh's destination. Often the dead were said to dwell in the realm of Osiris, a lush and pleasant land in the underworld. The solar vision of the afterlife, in which the deceased soul traveled with $\mathrm{Ra}$ on his daily journey, was still primarily associated with royalty, but could extend to other people as well. Over the course of the Middle and New Kingdoms, the notion that the akh could also travel in the world of the living, and to some degree magically affect events there, became increasingly prevalent ${ }^{7}$.

Ma'at as a deity was personified as a goddess, most often in a seated posture with one raised knee, holding a scepter in one hand and an ankh in the other. An ostrich feather crowns her head. Sometimes she has wings on each arm. Later on she was paired with Thoth as her counterpart, guiding the Boat of Re on either side. Maat as a concept of truth and order is a special kind of divinity in the Egyptian pantheon, not worshipped in the same religious fashion as the deities of Egypt. Only one small temple at Karnak, now in ruins, exists dedicated solely to her.

Living in Ma'at also meant that the deeds you perform in this life would be amply rewarded in the Land of Osiris. The salvation of the deceased depended on his heart weighing exactly like the feather of the Goddess Ma' at in the Balance of Truth at the Hall of Ma'at. The gods judged the deceased in his afterlife, if he or she has done wrong or right, the deceased is declared makkeru, "true of voice", if he or she is found worthy. Maat is central to ancient Egyptian religion, ancient Egyptians believe in many separate deities or only One with multiple manifestations, capable of assuming masculine, feminine and animal roles.

In those days, every culture had their particular divinities. The first thing a respectful traveler would was to go to the temple of the local god and pay his respects. The Egyptian mentions that it was the custom for one king to call upon another king with whom he was in peace to pay a tribute in gold. The precious metal was used to erect an image of his brother king's god. Both nations would thus benefit one with gold and the other with an image of his authority in 
Taiwo \& Daniel: Revisiting the Youruba Ethnogenesis...

his ally's land. Today, of course, Egyptians, whether Islamic or Christian, worship only one God and, although the ancient gods and goddesses are no longer worshipped, there is Maat bringing truth, justice and joy to the Black Land.

\section{The Connection of Egyptian Ma'at and Yoruba Ori: A Critical View}

In Egyptian religious belief, Ma'at has assumed a position of a goddess but without a peculiar sanctuary of worship. Ma'atis represented in the various shrines in the process of offertory sacrifices to other contemporary gods. In fact, the gods and goddesses have to live in accordance to the tenet of Ma' at. This does not exempt the humans who are expected to also keep to the tenets of Maat. These demands on both edges of divinity and humanity appear a fundamental requisite for a cosmological harmonization. Thus, it can be argued in Egyptian belief that Maat is the height of the Egyptian religion, and so, it is superior to the gods ${ }^{8}$.

Nevertheless, the only thing that comes closer to the Maat's phenomenon in the Yoruba belief is Ori. Ori could not be regarded as a god of goddess, though it is worshiped or appeased but there is no peculiar sanctuary for its worship. Hence, in terms of the functions of Ori, it ranks above the gods; the Yoruba that "Ori la ba ma bokaf' orisasile" that is, it is "Ori" (the spiritual head-figure of man) that should be appeased while the gods are ignored", Ori is superior to other gods. In fact, Ori is the maker of the gods in term of their status, functions in creation and personal characters. Hence, "awoneniOri shad a lanpeniOrisha" meaning that it is those made by Ori are known as gods. Anyway, the gods must keep to the terms of their "Ori". Besides, Ori must be appeased just as the Egyptians appease to fortify Ma' at against the attacks of evil. In same way, Ori can be attacked by wicked magic or evil, the Yoruba are to appease "Ori" so as not to subscribe to evil plot.

The pharaoh is the physical expression of the gods in fact, the son of Maat. Maat is conceived as being enthroned when pharaoh assumes the throne. Likewise, in Yoruba belief, the king is the next of kin to the gods, and it is believed that Ori enthrones kings as in "Ori lo da AlarasileAra", Ori lo da Ajerosileijero' Ori lo da 
Oranguns'ila" meaning that Ori enthrones Alara, Ajero and Orangun in their respective cities to be kings.

Ori and Ma'at also play unique roles in the harmonization of the human-divine cosmological arrangements. The Egyptians, pharaoh and the gods must keep to the tenets of Ma'at, it is not clear whether the tenet is in form of written codes. The Yoruba on the other hand must respect the demands of "Ori" not in form of coded laws, but the Yoruba finds out Ori demands through the "Ifa corpus". Above all, what is central to both ideologies is the institution of behavioural etiquette for the modification or moderation of human attitudes. The Yoruba believe that Ori demands character to function excellently well, likewise Ma'at in Egyptian faith.

Finally here, Maat is conceived as a pursuit of justice here and afterlife; Ori is one in Yoruba experience, what feature prominently is that of divine retribution or vengeance, Yoruba do say "Ori mi a da" meaning that "my creator will judge" Ori is seen as an extension of the supreme being in man, which has the capacity to reattribute evil for evil or good for good. The approach may be different, what appears relative is the fact that both Ma'at and Ori signify human justice and social order ${ }^{9}$.

\section{The Similarity of the Egyptian-Yoruba Thoughts on Afterlife and Burial Rituals}

The first connection here between the Egyptians and the Yoruba is the belief that is beneficial for both the living and the dead to conduct a befitting burial for the deceased. This is why in Yoruba land, people do revisit the burial of those who had died several years in the past but were unceremoniously buried.

In both Ancient Egyptian and Yoruba faiths, it is believed that a befitting burial for the deceased attracts good fortunes for the dead as well for the living. The family members in both religious traditions have roles and rites to fulfill. Also, it is the belief in both cultures that the deceased still maintain their earthly social statuses while in afterlife that is, the aristocrats, poor, peasants, the middle class would remain in their formal social stratification. Even the servants would continue to serve their master. 
Besides, in ancient Egypt and amongst the Yoruba, servants, loyalists, wives etc. are buried together with their masters such as kings, illustrious warriors, and the wealthy ones. Subsequently, in the historical development of the Yoruba, it was changed to linages, sculptures and animal blood to represent the king's subjects, just as the Egyptians bury the departed kings and adopted images and status. Again, in both cultures they provide for their needs in view of their belief that the deceased were travelling on a journey, thus, food items and other commodities such as clothing, jewelry, silver, money are buried with the corpse. They both enlarge the sizes of the graves to accommodate burial goods. Although, the Yoruba does not mummify their dead bodies like Egyptians, but both traditions believe in caring properly and burying the dead bodies.

Furthermore, the Egyptians and the Yoruba believed that the heart is the seat of intelligence, thus, the Egyptians remove the heart of the deceased and store it in a jar while the Yoruba in royal burial remove it an give it to a successor of king to eat. It is believed that the spiritual essence of the late king is transferred to the successor.

\section{(a) The Relation of the living with the dead}

The ancient Egyptians believed that the dead live among the living and that they have roles to play in daily human life. The Yoruba believe that they can attract the favour of the dead. Conversely, the dead can harm when they are mistreated before and afterlife. The Egyptians just seek a good afterlife for the dead and not due to fear. The Egyptians likely do not have regard for ancestor worship, reincarnation, transmigration, etc. as the Yoruba highly regard them $^{10}$.

\section{(b) Afterlife Journeys}

The Yoruba beliefs on the afterlife journey varies some believe that when a man dies, he or she takes up a journey to cross a river after paying a ferry man, who is to transport the dead across the river.

Similarly, the Egyptians also equate the resurrection of the dead to the seasonal tides of the Nile. The Egyptians have a different view of crossing the river; yet both religious traditions regard crossing of a river as part of the journey into afterlife. 
On the final route to the destiny of the dead, the Yoruba believe that the deceased must climb a mountain or that there is a gatekeeper who watches over the gate to the World of the dead. Some believe the World is invisible and partitioned from the world of the living while some believe that the world in beneath the ground. The Yoruba believe that the dead often visit village squares, market places etc. Whenever they are noticed by anyone who knows them, the deceased immediately leave for another destination. Yet, the dead would first appear before Olodumare who judges and redeploy the dead at what location he wants.

The Egyptians on the other hand believed that the deceased would be judged by the gods and if the deceased had lived in accordance to Ma'at, his or her "ba" will join the "kh" to be akh, which now proceed to the "Duat' or the netherworld.

\section{The Yoruba and Egyptian Linguistic Similarities}

Language is a very important aspect of culture. It is the book of the people's experience. According to Ferdinand de Saussure, the surest to prove a cultural contact between peoples is to adduce linguistic evidence. In his book titled (The General History of Africa) (1972), the author claimed that one of the largest inhabitants of Egypt were Yoruboid (Yoruba), thus, more than 500 vocabularies can be deduced in the ancient Egyptian language devoid of the mixture of Greco-Roman and Arab words. For example consider the table below:

Egypt words/ Yoruba words (including, words from Yoruba dialect from Diaspora)

1. Wu (Rise)

2.Ere (Python)

3. Horise (a great god)

4 Ged (to chant)

5.Sueq (a fool)

6. Ta (sell)

7.Enru (fear)

8. Kun or gun (brave)

9.Ma or mi (to breathe)
$\mathrm{Wu}$ (Rise)

Ere (Python)

Orise (a great god)

Igede/Ogede (chant)

Suegbe (a fool)

Ta (sell or offer)

Eru (fear)

Ekun (brave)

Mi (to breathe) 
Taiwo \& Daniel: Revisiting the Youruba Ethnogenesis...

$\begin{array}{lll}\text { 10. } & \text { Khu (to kill) } & \text { Ku (die) } \\ \text { 11. } & \text { Hika (evil) } & \text { Ika (evil } \\ \text { 12. } & \text { Edjo (cobra) } & \text { Ejo (snakes) } \\ \text { 13. } & \text { Horiwo (head) } & \text { Oriwo (head) } \\ \text { 14. } & \text { AK (male) } & \text { Ako (male) } \\ \text { 15. } & \text { Mu (water) } & \text { Mu (drink water) } \\ 16 . & \text { Do (river) } & \text { odo (river) } \\ 17 . & \text { Aru (mouth) } & \text { Arun (mouth)ilaje } \\ \text { 18. } & \text { Ash (invocation) } & \text { Ase (invocation) } \\ 19 . & \text { Po (many) } & \text { po (many/cheap) } \\ 20 . & \text { Budo (dwelling place) } & \text { Bu do (dwelling place) etc. }\end{array}$

Note: this is to indicate that the Yoruba words are somewhat identical to that of the ancient Egypt. Scholars also claimed that the eastern blocs of the Yoruba such as the Itsekiri, Ilaje, Ijebu and onoara, are more cognate with the Egyptian than those of Oyo or Ife. They can be regarded as the phonetic sound to the more fluid form of the Yoruba spoken by the Oyo ${ }^{11}$.

BolajiIdowu asserted that the word "Oritese" came from the Itsekiri-owo axis within the eastern Yoruba kingdom. This word "Oritese" is almost the same as the Egyptian "Horise"; thus, both words were names of great water divinities before becoming sky or heavenly divinities. Again, both words are derived from same identical etymological origins; Hori (Ori) means head in both Yoruba and Egyptian cultures. All of these linguistic similarities could not be accidental; there is indeed a historical intercourse between the Yoruba and Egyptians ${ }^{12}$.

\section{The Yoruba CulturalTie with the Nubians: An Anthropological - Historical Hermeneutics}

Since this study is about the religio-cultural similarities between the Yoruba and the ancient Egyptians, it would be inconclusive without a consideration of their anthropological pairings. This exposes a sociological question, would the Yoruba emerge from the white or brown olive-skinned Egyptians, which are the present face of Egypt? Definitely, if we consider Egypt as part of Africa, then the peoples of the land must be blacks.

According to Cheikh Anta Diop, prior to the ascension of king MenpeltyreRamesses all the Pharaohs of Egypt were black. The 
following kings such as king Horemheb, king Khafra, king Tutankhamun, Queen Cleopatra, Queen Nefertiti, king Piye who was the conqueror of Egypt, the master of the Nubia and the greatest of all the Cushite warrior kings, including the biblical pharaohs that Moses and Joseph knew, were black Africa Nubians, who were later referred to as Sudanese. It was around 1292 BCE at the establishment of $19^{\text {th }}$ dynasty that kings Ramesses brought the white or the brownish olive-skinned Euroasiatics and Arabs. The black Nubians overwhelmingly dominated the land and a good percentage belong to the social stratification of the middle class such as the theologians, clerics, artists, writers, poets, medics, artisans, builders, architects, astrologers, mathematicians, etc.

Nonetheless, ancient Egyptians called their homeland "Kmt", which is pronounced as "kemet", etymologically, the root associate with the "Kam" or "Ham", which refer to 'black people' in Hebrew tradition. Again, scholars such as Diop, William Leo Hanberry and AboubacryMoussa Lam, have argued that "Knnt" was derived from the skin colour of the Nile valley people who were blacks ${ }^{13}$.

The point here is that the incursions and the invasion of the Arabs was responsible for so many migrations of these black Nubians or Negroes even including the final batch of the ancient Cushites also migrated from Mecca and Medina after living in the Arab lands for thousands of years to join their African brothers and sisters in Ethiopia, Sudan and at the Nile valley in ancient Egypt; these Cushite migrants were the Yoruba thousands of years before the word "Yoruba" was invented.

These Cushite forefathers of the Yoruba led the famous world civilization in Egypt. They were learned, mystical and vast in philosophy, the arts, history, the mysteries of the age, science, anthropology etc. They believed in pantheons of gods and worship them, this religion was well accepted wherever they went and settled. In fact in Egypt, where they dwelt, the polytheistic religion became the cornerstone and the foundation of ancient Egyptian religious culture ${ }^{14}$.

Hence, many traditions in Yoruba world point to Egypt as a place of origin. It is clear that the Yoruba scientifically proven did 
not migrate to where they are now largely in the southwest of Nigeria at once. The Awujale of the Ijebu land has come out to say that the Ijebus were descendants of the Nubians, and also that the Itsekiri are speaking the original Ijebu language ${ }^{15}$. Conton argued that the Yoruba of Nigeria are believed by many modern historians to be descended from a people who were living in one banks of the Nile 2,000 years ago, who had a close contact with the Egyptians and the Jews even before 600 .

\section{Conclusion}

This study explored the cardinal religious concepts, and practices of both Egyptians and Yoruba religio-cultural traditions. It also considered the linguistic tie or similarity of the language spoken by the same peoples. This work is not just an attempt to tell the story but to access in a critical sense the various findings in order to ascertain their significance for the assumption of historical contacts between the Egyptian and Yoruba religious cultures.

$A b$ initio, that the Yoruba concept of Ori appeared a prototype of the Egyptian Ma'at. Both were not just religious or cultural phenomenon but a philosophical creation of a social agent saddle with the task of moderating and modifying the attitudes of creative beings; thus, bring about a social order of justice and equity and so effect cosmological harmonization of the universe. In its right, this is also scientific; the cohesive functions of the gods could be imagined as the elemental interactions of nature. This obviously requires the full participation of humanity in helping to sustain the integrity of nature; the peaceful co-habitation of the gods and humans.

Both Egyptian and Yoruba society in ancient times had vivid ideas about purpose of society and even nature. Though, such insinuations are empirically or scientifically conceived, they were not written. Thus, the religious languages of both the Egyptians and the Yoruba appear the imaginative codes of conveying and communicating such scientific experiences in their world, for natural order and ethical purposes.

Secondly, the traditions in both cultures about burial rituals are very close; few approaches may appear different but definitely in its intents shared the same concerns. Thus, these little variances 
indicate the various transformations that had taken place as a result of migration and social integration with the new place or places of settlement. Besides, the shared beliefs on the treatment of the departed spirits or the spirits of the dead show traits of ideological difference but both peoples are aware and stand to benefit either directly or indirectly from the proper treats of the spirits of the dead.

Nonetheless, the linguistic ties of the Egyptians and Yoruba language are too obvious to be ignored or considered as mere coincidence. The similitude of the vocabularies found as sharing same root in Yoruba and Egyptian language show that both religious cultures have interacted in the past; more so, that this claim is based on scientific proof and not on somewhat ancient narrative guess, calls for a deeper interest in the furtherance of this linguistic assertion pioneered by Saussure Ferdinand. However, this template appears convincingly proven that indeed both religion and culture had a contact or possible shared same origin or that the Yoruba emerged from that of the Egyptians.

Again, the anthropological and Historical Hermeneutical consideration of the Yoruba origin disapproves the white origin of the Yoruba to favour that of the black Egyptians, the Nubians. These Nubians were said to descend from the Cushites, who came from different parts of the East Mecca and Medina; they did not migrate initially to associate with African brothers and sisters in ancient Ethiopia and Sudan anyway, as a result of persecution and wars later join them. They were acclaimed as the forefathers of the Yoruba people who were responsible for the earliest Egyptian civilization. The incursion of the Arabs saw them migrated from mainland Egypt to other side of Nile valley and subsequently to where they are now. It should be noted that the model also appears convincing on the Egyptian origin of the Yoruba.

At all events, reexamining the Yoruba Ethnogenesis is rewarding because, it has brought to the front burner the semblances of the Egyptian culture and that of the Yoruba; using religious and cultural beliefs to prove this tie, this also includes a scientific demonstration of the language similarities to indicate a possible origin of the Yoruba from ancient Egypt. 
Taiwo \& Daniel: Revisiting the Youruba Ethnogenesis...

*Emmanuel Folorunso Taiwo, Department of Classics, University of Ibadan, Ibadan, Oyo State, Nigeria. Oyinkan01@yahoo.com

*Aghedo Paul Daniel Religious studies Department, University of Ibadan. 


\section{Endnotes}

${ }^{1}$ The oduduwa legend contends that the original ancestor of the Yoruba people came from the East' or 'mecca', and arrived at ileife, cf. Agai 2013a.13 \&Jonson 1921:5; folorunso 2003:84)

${ }^{2}$ Book of opening the Mouth, the Address to Re, translated by Budge, 1972 ${ }^{3}$ Agbai, 2013a

${ }^{4}$ Agai, 2013a 14; cf Lucas 1970; 412-413.

${ }^{5}$ Caroline Seawright, "Maat, Goddess of Truth, Balance Order". www. Google. com

${ }^{6}$ Demise Martin,(2008) Ma' at and order in African cosmology: A conceptual food for understanding in digamous knowledge

${ }^{7}$ E.Hornung. 1992.Idea into image, Timken-Princeton.

${ }^{8}$ Egyptians Gods@2001 - 2005, kingTutone one.com.

${ }^{9}$ Henrietta McCall.1990. Mesopotamia myths (USA University of Texas Press)

${ }^{10}$ Ibid. Yale University Press, 1999 (rev 2001)

${ }^{11}$ John Romer,1988. Testament (Guide publishing)

${ }^{12}$ Mark Collier, and Bill Manly, 1988. How to read Egyptian Hieroglyphs: Revised edition, Berkeley: University of California Press.

${ }^{13}$ Martin Denise, 2008. "Maat and Order in African Cosmology: A conceptual Tool for understanding indigenous knowledge".

${ }^{14}$ http://www.touregypt.net/godsofegypt/maat.htm. 
${ }^{15}$ http://www.assatashakur.org/forwn/kemetic-netern/13431-complexconcept-maat-kemetic-philosophy.html

\section{References}

Book of opening the Mouth, the Address to Re, translated by Budge 1972.

Caroline Seawright, "Maat, Goddess of Truth, Balance Order”. www. Google. Com (accessed 12/02/2014)

Demise Martin,2008.Ma'at and order in African cosmology: A conceptual food for understanding in digamous knowledge.

E. Hornung. 1992.Idea into image, Timken-Princeton.

Egyptians Gods@2001 - 2005, kingTutone one.com.

Henrietta McCall.1990.Mesopotamia myths, USA University of Texas Press.

.....2001.Mesopotamia myths, Yale University Press.

John Romer, 1988.Testament, Guide publishing.

Mark Collier,\& Bill Manly,1988. How to read Egyptian Hieroglyphs: Revised edition, Berkeley: University of California Press,

Martin Denise,2008 "Maat and Order in African Cosmology: A conceptual Tool for understanding indigenous knowledge".

Morenz Siegfried, 1973. Egyptian Religion. pp. 112 - 125.

Norman Rufus Colin Cohn.1993. Cosmos, Chaos and the World to come: The Ancient Roots of Apologetic Faith.

Power Anton, The Greek World, Psychology 303.

http://www.touregypt.net/godsofegypt/maat.htm.

http://www.kingtutone.com/gods/maat

http://www.ancientegypt.co.uk/gods/explore/maat.html http://www.anceintegypt.co.uk/glossay/viz 